\title{
Use of Chronic Care Management Among Primary Care Clinicians
}

\author{
Ashok Reddy, MD, MSc ${ }^{1,2}$ \\ Leab M. Marcotte, $M D^{1,2}$ \\ Lingmei Zhou, MS $S^{1,2}$ \\ Stephan D. Fibn, MD, MPH \\ Josbua M. Liao, MD, MSc $c^{1,2,3}$ \\ 'Department of Medicine, University \\ of Washington School of Medicine, Seattle, \\ Washington \\ ${ }^{2}$ Value \& Systems Science Lab, Seattle, \\ Washington \\ ${ }^{3}$ Leonard Davis Institute of Health \\ Economics, University of Pennsylvania, \\ Philadelphia, Pennsylvania
}

Conflicts of interest: Dr Liao reports personal fees from Kaiser Permanente Washington Research Institute, none of which are related to this manuscript. All other authors report none.

\section{CORRESPONDING AUTHOR}

Ashok Reddy MD, MSc Department of Medicine, University of Washington

1660 S. Columbian Way

Seattle, WA 98108

Ashok.Reddy@va.gov

\begin{abstract}
The Centers for Medicare and Medicade Services (CMS) initiated chronic care management (CCM) codes to reimburse clinicians for coordination activities, but little is known about uptake over time. We find that primary care clinicians drove increasing use over 4 years-a trend that may reflect either new coordination activities or new reimbursements for existing activities. That $5 \%$ of chronic care management was denied by Medicare underscores the need for future work evaluating facilitators and barriers to use. Such insight is especially vital given the large number of eligible beneficiaries that have not received chronic care management to date, as well as the limited number of clinicians who currently deliver these services.
\end{abstract}

Ann Fam Med 2020;18:455-457. https://doi.org/10.1370/afm.2573.

\section{INTRODUCTION}

$\mathrm{N}$ early two-thirds of the 40 million Medicare fee-for-service patients nationwide live with multiple chronic conditions. ${ }^{1,2}$

These individuals incur over $90 \%$ of all Medicare spending while frequently having care fragmentation. ${ }^{3}$ To address these issues, Medicare began reimbursing clinicians in 2015 for care management via chronic care management (CCM) codes.

Chronic care management seeks to support the over 180,000 primary care physicians nationwide who care for Medicare patients, providing longitudinal, non-visit-based care (eg, ongoing disease management and coordination across clinicians). ${ }^{4}$ Clinicians can deliver chronic care management to patients with multiple chronic conditions each month, and services must include a comprehensive care plan that is established, monitored, or revised. Chronic care management services are encapsulated by 4 billing codes. The original current procedural terminology (CPT) code 99490 reimburses clinicians for up to 20 minutes of non-face-to-face care management services. In 2017, additional codes, CPT 99487 and 99489, were introduced to provide higher reimbursement for complex care management. An add-on code, G0506, was introduced in 2017 to account for instances in which clinicians personally perform care planning activities upon initiation of chronic care management services.

Although uptake of chronic care management has been limited to date, with only 16,459 clinicians delivering these services to 684,584 Medicare patients over the first 2 years (2015 to 2016), Medicare has continued to emphasize the code in payment policy. ${ }^{5}$ Policy makers have expanded chronic care management codes over time to encompass complex care and enable both physician and non-physician team members to deliver chronic care management services. The 2020 Medicare physician fee schedule increases choronic care management payments and expands services to patients with 1 medical condition. ${ }^{6}$ Despite increasing policy emphasis, however, little is known about longer-term national trends in chronic care management use, particularly regarding services provided to complex patients. 
Figure 1. Trends in CCM use and payment, 2015-2018.

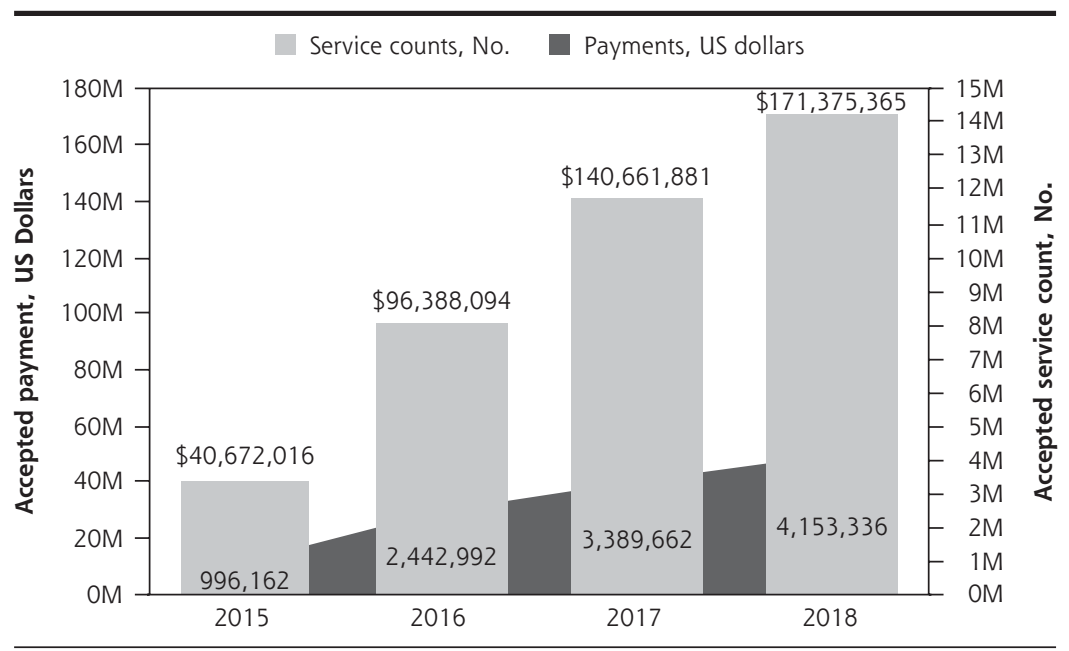

$\mathrm{CCM}=$ chronic care management

Note: Source is https://www.cms.gov/Research-Statistics-Data-and-Systems/Statistics-Trends-and-Reports/ Physician-Supplier-Procedure-Summary/index.html

Table 1. CCM Services Accepted and Denied by Medicare

\begin{tabular}{|c|c|c|c|c|}
\hline Year & $\begin{array}{l}\text { Accepted CCM } \\
\text { Services (n) }\end{array}$ & $\begin{array}{l}\text { Payments for } \\
\text { Accepted CCM } \\
\text { Services } \\
\text { (US Dollars) }\end{array}$ & $\begin{array}{l}\text { Denied CCM } \\
\text { Services }(n)\end{array}$ & $\begin{array}{c}\text { Potential Payments } \\
\text { for Denied CCM } \\
\text { Services } \\
\text { (US Dollars) }\end{array}$ \\
\hline 2015 & 996,162 & $40,672,015$ & 60,222 & $3,849,042$ \\
\hline 2016 & $2,442,992$ & $96,388,094$ & 96,836 & $7,121,281$ \\
\hline 2017 & $3,682,373$ & $161,476,779$ & 176,768 & $13,810,823$ \\
\hline 2018 & $4,647,807$ & $205,941,845$ & 264,222 & $18,924,714$ \\
\hline Total & $11,769,335$ & $504,478,733$ & 598,048 & $43,705,860$ \\
\hline
\end{tabular}

\section{METHODS}

\section{Data Source and Analysis}

We used publicly available 2015-2018 Medicare data capturing $100 \%$ of CCM claims submitted to Medicare by physicians nationwide. ${ }^{7}$ For each year, we calculated service counts and payments for both paid and denied CCM services. We also compared utilization and payment by physician specialty (internal medicine, family medicine, general practitioners, geriatric medicine collectively "primary care physicians"; neurology, infectious disease, cardiology, nephrology, medical oncology, pulmonary disease, endocrinology, psychiatry, preventive medicine categorized as "medicine subspecialists"; all other specialties as "others"). We used $\chi^{2}$ tests to compare categorical variables. Statistical tests were 2-tailed and significant at $\alpha=0.05$. Analyses were performed in SAS, Version 9.4 (SAS Institute, Inc). Institutional review board approval was not obtained given the publicly available, de-identified nature of the data.

\section{RESULTS}

Service counts and corresponding payments for CCM increased between 2015 and 2018 (Figure 1). Original CCM (CPT 99490) represented $93 \%$ of all CCM services, complex CCM care management services (CPT 99487, CPT 99489, and G0506) represented only $7.9 \%$ of CCM services in 2017 and $10.6 \%$ in 2018 . Across all years, CCM was most commonly delivered by primary care physicians $(78 \%$ vs $8 \%$ medicine subspecialties vs $14 \%$ others, $P<.0001)$. Among primary care physicians, CCM use increased from 810,289 services in 2015 to $3,401,546$ in 2018, representing $\$ 33,718,816$ and $\$ 151,897,061$ in payments, respectively. Similarly, CCM use also increased among medicine subspecialists from 60,511 services in 2015 to 448,821 in 2018 . Overall, $4.8 \%$ of submitted CCM services were denied by Medicare (Table 1). Denials represented $5.7 \%$ of all submitted CCM in 2015 and $5.4 \%$ in 2018 .

\section{DISCUSSION}

We found that CCM use increased over the 4-year period studied, driven predominantly by primary care physicians, and that newer codes represented a small proportion of overall use. The percentage of denied services also remained consistent since the introduction of CCM. These findings pose 2 important policy and practice implications.

First, primary care and other clinicians appear to have increasingly used CCM to coordinate care for patients with multiple chronic conditions. This trend is encouraging given that fragmented care adds an estimated $\$ 75$ billion in health care costs annually. ${ }^{8}$ Our results lend support to Medicare's decision to continue emphasizing CCM as part of payment reform in an effort to improve care improvements and reduce cost.

Second, given that newer codes represent the minority of services provided, it is uncertain whether the availability of CCM reimbursement prompts clinicians to implement new coordination activities, or if clinicians use CCM to capture coordination activities 
they are already delivering to patients with multiple chronic conditions. Although low, the observation that $5 \%$ of claims are denied may suggest that the administrative burden for billing these codes discourage many clinicians from submitting claims at all, even if some of all CCM services are actually being delivered. ${ }^{9}$ It is also unclear whether CCM payments are sufficient to support the investment in staff, administrative resources, and workflow changes needed to change practice. $^{10}$ These factors could limit use of newer complex CCM codes as well as forthcoming codes targeted at patients with a single chronic disease. ${ }^{6}$

Limitations of this study include descriptive design and the lack of granular practice- and patient-level data. Analyses that were beyond the scope of our study and should be the focus of future work include evaluation of whether CCM use corresponds to new activities vs new reimbursement for existing activities. Nonetheless, to our knowledge, this study is the first to describe longer-term trends in CCM use, with an emphasis on complex care management and denied services among primary care clinicians as key providers of coordination services. As a result, our results reinforce CCM as a key policy and the need for large-scale evaluations to address several critical payment and implementation issues.

To read or post commentaries in response to this article, see it online at https://www.AnnFamMed.org/content/18/5/455.

Key words: Medicare; primary care issues; care coordination; chronic care: disease management/care management

Submitted November 21, 2019; submitted, revised, February 4, 2020; accepted February 11, 2020.

\section{References}

1. Lochner KA, Goodman RA, Posner S, Parekh A. Multiple chronic conditions among Medicare beneficiaries: state-level variations in prevalence, utilization, and cost, 2011. Medicare Medicaid Res Rev. 2013;3(3):mmrr.003.03.b02.

2. KFF's State Health Facts. KFF analysis of the CMS Medicare Advantage enrollment and Landscape files, 2010-2018, total number of Medicare beneficiaries. https://www.kff.org/medicare/stateindicator/total-medicare-beneficiaries/?currentTimeframe $=0$ Esort Model =\%7B\%22colld\%22:\%22Location\%22,\%22 sort $\% 22: \% 22$ asc $\% 22 \% 7 D$.

3. Blumenthal D, Chernof B, Fulmer T, Lumpkin J, Selberg J. Caring for high-need, high-cost patients - an urgent priority. N Engl J Med. 2016;375(10):909-911.

4. MEDPac. Report to Congress: Medicare and the health care delivery system 2019. https://medpac.gov/docs/default-source/reports/ jun19_medpac_reporttocongress_sec.pdf. Published 2019.

5. Schurrer J, O'Malley AS, Wilson C, McCall N, Jain N. Evaluation of the Diffusion and Impact of the Chronic Care Management (CCM) Services: Interim Report. Washington, DC: Mathematica Policy Research; 2016.

6. Centers for Medicare and Medicaid Services (CMS). Proposed rule physician fee schedule. https://www.federalregister.gov/documents/2019/08/14/2019-16041/medicare-program-cy-2020-revisions-to-payment-policies-under-the-physician-fee-schedule-andother. Published Aug 14, 2019.

7. Centers for Medicare and Medicaid Services (CMS). Physician/ Supplier procedure summary. https://www.cms.gov/ResearchStatistics-Data-and-Systems/Statistics-Trends-and-Reports/PhysicianSupplier-Procedure-Summary. Accessed Sep 19, 2019.

8. Shrank WH, Rogstad TL, Parekh N. Waste in the US health care system: estimated costs and potential for savings. JAMA. 2019.

9. Gardner RL, Youssef R, Morphis B, DaCunha A, Pelland K, Cooper E. Use of chronic care management codes for Medicare beneficiaries: a missed opportunity? J Gen Intern Med. 2018;33(11):1892-1898.

10. O'Malley AS, Sarwar R, Keith R, Balke P, Ma S, McCall N. Provider experiences with chronic care management (CCM) services and fees: a qualitative research study. J Gen Intern Med. 2017;32(12): 1294-1300. 